\title{
Consumers' Satisfaction with 7up Packaging: an empirical Analysis
}

\author{
Akabogu, Okey Christopher \\ Department of Marketing Faculty of Management Sciences Anambra State Univeristy, Anambra State, \\ Nigeria
}

\begin{abstract}
This study focuses on the lacuna apparently extant because of the, probably, insufficient use of theoretical frameworks to measure and analyze packaging influences on consumers' satisfaction with 7up soft drink in Nigeria. The "VIEW" theory of packaging is the operationalized theoretical framework on which this study rests. Using a structured questionnaire, the influences of the "VIEW" packaging variables on consumers' satisfaction with 7up soft drink were obtained through a survey of a convenience sample of 300 consumers of 7 up in Awka, capital city of Anambra State, Nigeria. The data obtained were computer analyzed using multiple regression analysis and analysis of variance (ANOVA) procedures. The study found that the "VIEW" theoretical framework explained about $46 \%$ of the variability in consumers' satisfaction with 7 up in the study area. Only the Visibility (V) and Information (I) components of the "VIEW" theoretical framework significantly influenced consumers' satisfaction with 7up in the study area. Except for the education segments, the study found significant differences in satisfaction across the age and income segments of consumers of 7up in the study area.
\end{abstract}

Keywords: "VIEW", packaging, 7up, consumers' satisfaction, Nigeria

\section{Introduction}

Literature on packaging points to mounting interest in packaging as a seminal variable in the promotion of a product or service, as also argued in [1,2]. My previous discussions on the subject of packaging surmised that beyond the traditional consideration of packaging as a shielding device for a product as it transits from the producer to the consumer, packaging is being reevaluated by manufacturers and marketers to include using a product package as an influential, and salient 'salesperson'. As I have discussed previously, the escalating recognition of packaging in the arena of promotion, one of the marketing mix variables, has been apparently lightly examined in the literature. In the literature, there are several studies on packaging as a protective device, but the literature on packaging as an increasingly salient, and a potentially potent promotional tool has been rather thin, both within and outside Nigeria. I have previously also pointed out that some early works on the promotional role of packaging outside Nigeria include [4], [5], [6], [7]. Recent works and writings on the promotional role of packaging include [8], [9], [10], [11], [12], [13], [14], [15], [1, and 2].

$[1,2]$ considered and empirically tested the packaging theory by [4], one of the outstanding theoretical works in the literature in assessing the effects of packaging on consumers. [4] advanced the "VIEW" theory of assessing packaging effects, keeping in view the package's expected performance and contribution in the promotional mix. The "VIEW" theory of packaging, as enunciated by [4], prescribes a paradigm of four variables for evaluating a package design. The four criteria are, as cited in [5] and as utilized in [1,2], ' $\mathrm{V}$ ' for Visibility of the package that makes the package stand out in an array of products displayed, for instance, in a supermarket or shop; 'I' for the Information provided by the package that informs the consumer of key product attributes and expected benefits; 'E' for the Emotional appeal the package provides the consumer by way of conveying an image of modernity, luxury, etc.; and ' $\mathrm{W}$ ' for the Workability of the package that suggests to the consumer the ability of the package to perform its function of protecting and preserving the freshness of the contents after opening.

This study, as in my previous studies on packaging, rests on the "VIEW" theory of packaging as the theoretical framework for an empirical measurement and analysis of the influences of the "VIEW" variables on consumers' satisfaction with bottled 7up in Awka, a capital city of Anambra State, Nigeria. The "VIEW" theoretical framework is illustrated in the schematic below which identifies some variables that may be influenced by the packaging variables coalesced in the "VIEW" packaging theory. 


\section{"V I E W" THEORY

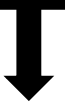 \\ "VIEW" VARIABLES \\ VARIABLES INFLUENCED BY "VIEW" VARIABLES}

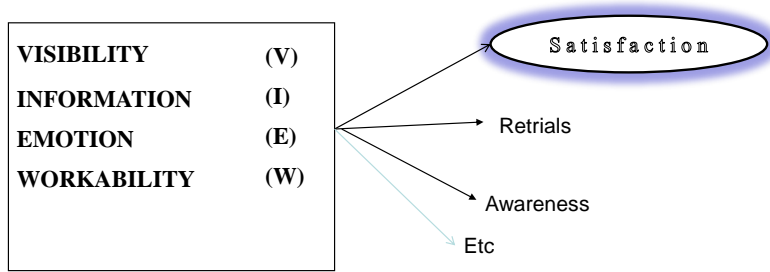

Source: Adopted from $[1,2]$

To exemplify the escalating attention given to packaging in the consumer goods categories, not too long ago, [15] reported on a package redesign of 7up as follows:

Marketing manager Tim Davie, 27, who joined Pepsi last December from Procter \& Gamble, says he didn't like the package design of 7up, a brand that Pepsi owns outside the U.S. After some consumer research, he hired a graphics firm from suburban London to make the greens on the can greener and its 7 up bubbles swirly and three- dimensional. [15]

In the geographical area of this study, Awka, the capital city of Anambra State, Nigeria, the 7up family brand is offered in the canned and bottled (plastic and glass) varieties. Even though the Coca Cola family brand stands tall in the soft drink global competition landscape, the 7up family brand of soft drink is also a global family brand that competes closely with Coca Cola and Pepsi family brands in the global soft drink market. Only the bottled version of 7up is of interest in this study. In Nigeria, bottled 7up is produced and widely distributed by The Seven Up Bottling Company, Plc. [24]. In this study, hereafter, 7up is used to refer to only the bottled version of 7 up.

As I have previously stated, in Nigeria, studies on packaging include [16], [18]. [16] through an empirical work on packaging in Nigeria summarized a ranking of some package attributes in terms of their importance in evaluating a package. However, [16] did not suggest that the ranking was in relation to promotional influence of the attributes, nor did the study indicate that a methodical concept such as the "VIEW" concept was applied to evaluate packaging as a promotional tool in Nigeria. The work on sachet water brands by [17] examined the health aspects of packaged water, but did not visualize packaging as a promotional tool. The findings from the work of [17] also did not suggest that the "VIEW" concept or any other systematic approach was used in evaluating the sachet's influence as a package. In [1], I showed through an empirical study that the "VIEW" theory of packaging is significant and relevant in measuring the promotional influence of the sachet of Peak milk on consumers' retrials of sachet Peak milk in Nigeria. From [1, 2], promotional influence is an outcome variable resulting from the impact of some promotional variables, including packaging variables such as described above in the "VIEW" theory of packaging. Depending on the promotional objectives, promotional influence, as a composite variable, may be measured in terms of the increase in consumers' awareness of the product, consumers' purchase intent/trials/retrials of the product, consumers' attitudes towards the product (e.g., consumers' satisfaction with the product), [5]. Satisfaction with a product, for instance, may consequently give birth to brand loyalty which in turn and in time may positively improve the company's bottom-line of profit and brand equity. Consumers' satisfaction with a product and brand loyalty may also vary across socio-economic and demographic levels, as suggested in $[1,2]$. Consequently, in the context of this study, for targeted promotional purposes, it is relevant for the producers and marketers of 7up to keep in perspective the variations that may be extant or absent in consumers' satisfaction with 7up across socioeconomic and demographic segments of 7 up consumers.

In the literature, there appears to be a dearth of evidence that a packaging theory has been used to study the influence of packaging variables on consumers' satisfaction with 7up in Nigeria. This study, applying the "VIEW" packaging theory, measured and analyzed the influences that the variables encapsulated in the "VIEW" theoretical framework have on consumers' satisfaction with 7up in Awka, capital city of Anambra State, Nigeria. Consequently, this study was birthed by the desire to fill in the lacuna that may be extant due to the non-use of packaging theories in measuring and analyzing the influences that 7 up packaging may have on consumers' satisfaction with 7up in parts of Nigeria. 


\subsection{Statement of the problem}

As a result of the foregoing synopsis, in relation to consumers' satisfaction with 7up in different parts of Nigeria, 7up packaging may be significantly influential on consumers' satisfaction with 7up. Consequently, the research problem focuses on the lacuna which probably exists due to the non-application of theoretical frameworks to empirically measure and analyze the influences of packaging variables on consumers' satisfaction with 7up in different parts of Nigeria, using Awka, capital city of Anamabra State, Nigeria, as a study slice.

\subsection{Objectives}

In this study, the influences of the "VIEW" variables are captured by the consumers" satisfaction with 7up. Adopting the approach in [1,2], the components of "VIEW" are the packaging variables whose influences on consumers' satisfaction with 7up were measured and analyzed. Therefore, using the variables in the "VIEW" concept of packaging, this study evaluated how consumers' satisfaction with 7up were influenced by the packaging variables in the "VIEW" theory of packaging, using data from consumers of 7up in Awka, with the following specific objectives which are to:

1. identify the packaging variables in the "VIEW" theory of packaging that significantly influence or drive consumers' satisfaction with 7up

2. determine if, given the influences of the "VIEW" variables, consumers' satisfaction with 7up varies significantly across socioeconomic and demographic categories

\subsection{Research questions}

In order to accomplish the objectives of this study, the following research questions (RQs) were addressed:

RQ1: Are consumers' satisfaction with 7up significantly influenced or driven by the variables coalesced in the "VIEW" theory of packaging?

RQ2: Given the influences of the "VIEW" variables, across socio-economic and demographic categories, are there significant variations in consumers' satisfaction with 7up?

\subsection{Research hypotheses}

The following research hypotheses, in null forms, were set up to answer the research questions posed in this study.

Ho1: Consumers' satisfaction with 7up is not significantly influenced or driven by the variables coalesced in the "VIEW" concept of packaging.

Ho2: Given the influences of the "VIEW" variables, across the socio-economic and demographic categories, there are no significant differences in consumers' satisfaction with 7 up.

\subsection{Scope of the study}

Some of the discussions in this section may have some congruency with my previous discussions in other packaging studies. The scope of this study is delimited to packaging in relation to consumer products, using 7 up in a part of Nigeria as a study slice. Packaging is often considered as part of promotion, one of the $4 \mathrm{ps}$ of marketing [23]. However, packaging, based on literature and studies such as [1,2], arguably, should be considered as an additional salient, silent and potent ' $p$ ' in the marketing mix, given the escalating attention that packaging is getting in contemporary marketing strategy. In this study, packaging was delimited in scope to the theoretical framework, "VIEW" theory of packaging, which is composed of four characteristics that stipulate what a package design should include in order to influence consumers' behavior, attitude, and opinions about a product. The four criteria considered in the "VIEW" concept of packaging are the visibility (V), information (I), emotion (E), and workability (W) attributes that should concomitantly influence consumers' behaviors, attitudes, and opinions. The outcomes of the "VIEW" influences are expected to be behavioral or/and attitudinal, and in this study an influence of "VIEW" is measured by consumers" satisfaction with 7 up. The geographical scope of the study is Awka, a commercial city which is also the capital of Anambra State, Nigeria. As I noted previously, Anambra State of Nigeria consists of a constellation of closely related cultural groups, in terms of language, customs and traditions, with nuances that may or may not be distinguishable, with a linguafranca, English.

The study unit scope was only the adult consumers of 7up in Awka, Anambra State, Nigeria, who indicated that 7 up was their regular brand of soft drink. Of all the members of the 7 up family brand available in the soft drinks market in the area of study, only the bottled 7up, referred to in this study simply as 7up, is the brand of interest in this study. 
Several limitations were encountered in this study. Of particular note is that the concept of consumerbased marketing research is perhaps still in its infancy in many parts of the world, including the part of Nigeria in this study where the literacy level may also be an issue, even as I noted in my previous discussions. Nonetheless, the constraints and limitations were prudently handled so as to have uncompromised findings from the study.

\section{Materials and methods}

In $[1,2,3]$, I pointed to the existence of quantitative and qualitative research methodologies in the literature on research methodology, and that unlike qualitative methodology, quantitative methodology uses quantifiable and structured data as were collected and used for this study. The quantitative methodological approach used in this study permitted robust statistical analysis that engendered inferences and recommendations.

Also, in [1,2,3], I discussed issues relating to research design, various aspects of data collection, data collection instrument, and those discussions are applicable in this study as well. The research design used for this study is the survey method. The survey method involved a descriptive, single cross-sectional design in which non-probability sampling methods (convenience and judgmental sampling methods) were used to obtain a one-time (single cross-sectional) sample from the qualified population of 7 up consumers in the study area. As in my other packaging studies, quantitative methodology was used on the assumption that consumers' satisfaction with 7up and the influences of the "VIEW" variables on consumers' satisfaction with 7up can be measured on a continuous scale, and thus be treated as interval variables that possess means and variances which can be statistically analyzed. The population for the study is only the adult consumers of 7 up who indicated that 7 up was their regular brand of soft drink in Awka, Anambra State, Nigeria. Anambra state, one of the thirty six states of Nigeria, has a population of about 4.1 million people, which is about $3 \%$ of Nigeria's 140.5 million people [18]. There was no database of adult consumers of 7 up who indicated that 7 up was their regular brand of soft drink in Awka, Anambra State, Nigeria, and resided in Awka. As a result of this, no sampling frame of the said consumers existed at the time of this study. As I indicated previously, [19] suggests the use of a convenience sample of at least 200 for a study such as this, because a probability sample could not be used, since no sampling frame existed. A convenience/judgmental sample size of 300 respondents was used for this study. The convenience sample was obtained from small shops, shopping kiosks, supermarkets, and university campus areas within Awka city. The respondents were judgmentally and politely intercepted at those places and requested to willingly participate in the survey, in a face to face setting. Measurements on the influences of the "VIEW" packaging variables on the consumers' satisfaction with 7up were obtained from the respondents using a structured questionnaire (see appendices). In my previous discussions, literature shows that consumer satisfaction with products and services can be measured on continuous scales of the Likert type [19]. Leaning on the interval characteristics that consumers' satisfaction can take, as espoused in the literature, a structured questionnaire containing interval variables was used for data collection in the study. The interval variables on the questionnaire were used to measure consumers' satisfaction with 7up, and the influences that consumers think the "VIEW" variables have on their satisfaction with 7up. In [1,2, and 3], typologies of reliability tests in the literature were discussed. This study used SPSS to conduct the Cronbach's alpha reliability test [18]. A convenience sample of 50 consumers of 7 up in Awka was used to pretest the questionnaire, and Cronbach's alpha was computed from the pretest data, using the SPSS computer software. A value of approximately .75 was obtained for Cronbach's alpha, thus yielding a high internal reliability. From the battery of validity tests that exist in the literature, the face or content validity test was used to validate the questionnaire, and the questionnaire was evaluated for content relevance by six marketing practitioners in the study area. The area of study from which primary data were collected is Awka, Anambra State, Nigeria. A survey method of data collection was used to collect primary data from adult consumers of 7 up who indicated that 7 up was their regular brand of soft drink in Awka. Only primary data were used in this study.

\subsection{Analytical procedures}

The analytical approaches used in this study were adopted from my previously published packaging studies in $[1,2]$. One of the objectives of this study was to identify the variables in the "VIEW" concept of packaging that significantly influence or drive consumers' satisfaction with 7up. As I mentioned previously, literature suggests that packaging variables may drive consumers to buy a product [21], [22]. The possible association between consumers' satisfaction with 7up in Awka, and the "VIEW" packaging variables was analyzed using an associative model approach. To accomplish this objective, through testing the related hypotheses in the study, computerized associative modeling involving the use of multiple regression analysis was used to evaluate the influences which the "VIEW" variables have on consumers" satisfaction with 7up. Consumers' satisfaction with 7up is the dependent variable whose behavior is explained by the size of the coefficient of multiple determination, R-squared, yielded by the independent variables, the "VIEW" variables. 
From literature in [19], R-squared, in this instance, is the percentage of variability in consumers' satisfaction with 7up that is explained by the "VIEW" variables.

Another objective of the study was to determine if, given the possible influences of the "VIEW" variables, consumers' satisfaction with 7 up varies significantly across socioeconomic and demographic categories. To accomplish this objective, by testing the hypotheses in the study, computerized analysis of variance (ANOVA), with post hoc multiple means comparisons using the Duncan option with overlap analysis, was used to compare the mean influences which the "VIEW" variables have on consumers' satisfaction with 7 up in Awka.

\subsection{Assumptions}

As I have also previously discussed in [1,2,3] concerning assumptions in a study such as this, the notion that statistical inferences can be made on the basis of non-probability sample information, such as information obtained through convenience and judgmental sampling methods, was a 'painful' assumption that must be noted. The results from a non-probability sample may not be generalized to the population, simply because the convenience and judgmental sampling methods do not produce representative samples. Even though large sample sizes of $n>30$ in this study support statistical assumptions of normality of the sample means, yet the question of generalizability of the inferences made remains an arguable issue. However, [19] notes that even though convenience sampling has its limitations, yet it is used in huge market research surveys, and the author recommends sample sizes that are experientially suitable for market research surveys involving non-probability sampling [19]. The assumption that consumers' satisfaction and the influences of the "VIEW" variables on consumers' satisfaction can be measured on continuums bearing the semblance of interval scales may be arguably overbearing. [22] posited that there was some controversy surrounding the use of itemized rating scales that are used to measure variables that may be non-continuous. To worsen the pain in the assumption of continuity in the scale of measurement, some other requirements according to theoretical statistics may not have been met [19]. However, [19] opined that, often, the statistical theory requirements are satisfied in pragmatic data analyses involving analysis of variance and regression analysis, thus making them commonly used analytical techniques. Furthermore, the assumption that the variables involved in the study need not be transformed into other forms, such as log-linear, quadratic, and other forms, may be erroneous. The assumptions made in the study were by no means exhaustive.

\section{Theory/Calculation}

The theory supporting this study rests on the framework that the packaging variables encompassed in "VIEW" influence consumers' satisfaction with 7up.

The hypotheses set up to determine the influences of the "VIEW" variables on consumers" satisfaction with 7up, and the variations in satisfaction among the socioeconomic and demographic segments of 7 up consumers, were respectively tested using computerized multiple regression analysis, and analysis of variance, as depicted in TABLES I, IIA, IIB, and IIC, below.

Table I

Ho1: Consumers' satisfaction with 7 up is not significantly influenced or driven by the variables encapsulated in the "VIEW" concept of packaging.

$\begin{array}{llllll}\text { "VIEW" Variables } & \text { Beta coefficient } & \text { Std Error } & \mathrm{t} & \text { P-value } & \text { Sig. level } \\ \text { Visibility(V) } & .227 & .049 & 4.617 & .000 & .01 \\ \text { Information(I) } & .462 & .043 & 10.640 & .000 & .01 \\ \text { Emotion(E) } & -.029 & .056 & .521 & .603 & \text { NS } \\ \text { Workability(W) } & -.011 & .052 & .206 & .837 & \text { NS }\end{array}$

Note: $\mathrm{R}^{2}=.458$

In the tests of hypotheses captured in the multiple regression output in TABLE I, satisfaction is the dependent variable. The tests of hypothesis in TABLE I indicate that only Information (I) and Visibility (V) are significant positive drivers of consumers' satisfaction with 7 up at the .01 level of significance $(\mathrm{p}=.000)$. With an $\mathrm{R}^{2}=.458$, the "VIEW" variables simultaneously explain about $46 \%$ (.458) of the variation in satisfaction. The seemingly high explanatory power of the "VIEW" variables point to the strong influence that the packaging variables coalesced in the "VIEW" concept, in the context of this study, have on consumers' satisfaction with 7up in the study area. 


\section{Table IIA}

Ho2: Given the influences of the "VIEW" variables, across the age segments there are no significant differences in the consumers' mean satisfaction with 7 up

\begin{tabular}{lclll|l} 
Age Segments & $\mathrm{n}$ & $\begin{array}{l}\text { Consumers' } \\
\text { Satisfaction }\end{array}$ & Mean & \multicolumn{2}{c}{ Groupings/Overlap } \\
25 to $35 \mathrm{yrs}$ & 102 & 3.95 & $\mathrm{~A}$ & \\
36 to $50 \mathrm{yrs}$ & 102 & 3.68 & $\mathrm{~A}$ & $\mathrm{~B}$ \\
Above $50 \mathrm{yrs}$ & 96 & 3.49 & & $\mathrm{~B}$ \\
& & & $P=.125$ & $\begin{array}{l}P=.296 \\
P\end{array}$
\end{tabular}

The ANOVA that produced the results in TABLE IIA is significant at $.05(\mathrm{p}=.036)$. TABLE IIA shows that, given the influences of the "VIEW" packaging variables, there are significant differences in consumers' mean satisfaction with 7 up across the age segments in the study area. The means grouped with the same alphabets are comparable or equal at the stated $P$ values. Given the influences of the "VIEW" variables, mean satisfaction with 7 up is significantly higher in the 25 to 50 years age range in the study area.

\section{Table IIB}

Ho2: Given the influences of the "VIEW" variables, across the income segments, there are no significant differences in the consumers' mean satisfaction with 7up.

\begin{tabular}{llll|c} 
Income Segments & $\mathrm{n}$ & Consumers' Mean Satisfaction & Groupings/Overlap \\
Less than N50,000 & 78 & 4.14 & $\mathrm{~A}$ & \\
AboveN200,000 & 95 & 3.69 & \\
N50 to N200,000 & 127 & 3.46 & $P=1.000$ & $\begin{array}{c}\text { B } \\
P=.186\end{array}$
\end{tabular}

The results in TABLE IIB emanated from an ANOVA that is significant at .01 $(\mathrm{p}=.001)$ Given the influences of the "VIEW" variables, the results in Table IIB indicate that there are significant differences in the consumers" mean satisfaction with 7 up across the income segments in the study area. The means within the same grouping alphabets are comparable or equal at the stated $P$ values. Given the influences of the "VIEW" variables on consumers in the study area, the income group with less than N50, 000 per month shows a significantly higher mean satisfaction with 7 up than the other income segments which have comparable mean satisfaction with 7 up.

\section{Table IIC}

Ho2: Given the influences of the "VIEW" variables, across the education segments, there are no significant differences in the consumers' mean satisfaction with 7up.

$\begin{array}{lclll}\text { Education Segments } & \mathrm{n} & \begin{array}{l}\text { Consumers' } \\ \text { Satisfaction }\end{array} & \text { Mean } & \text { Groupings/Overlap } \\ \text { Less than Secondary } & 97 & 3.88 & \mathrm{~A} \\ \text { University } & 108 & 3.66 & \mathrm{~A} \\ \text { Secondary } & 95 & 3.60 & \mathrm{~A} \\ & & & P=.149\end{array}$

The results in TABLE IIC were produced from an ANOVA that is not significant $(\mathrm{p}=.280)$. From TABLE IIC, given the influences of the "VIEW" variables, with respect to education, there is no significant difference in the consumers' mean satisfaction with 7 up across the education segments considered in the study area. The means are comparable or equal at the stated $P$ values.

\section{Conclusion}

From the preceding analysis in TABLES I, IIA, IIB, and IIC, the following conclusions emanated.

1. The "VIEW" packaging variables are conjointly significant in influencing consumers' satisfaction with 7up in the study area. An R-squared of $46 \%$ implies that the packaging variables in the "VIEW" theory explain about $46 \%$ of the variability in consumers' satisfaction with 7 up. Thus, in the context of this study, the "VIEW" theoretical framework significantly supports a conclusion that 7up packaging may be highly relevant in understanding what drives consumers' satisfaction with 7up in the study area. 
2. Given the packaging variables in the "VIEW" theory of packaging, only the visibility (V) and information (I) components of the theoretical framework significantly drive consumers' satisfaction with 7 up in the study area. With $P=.000$, Information (I) and Visibility (V) of 7up packaging both significantly and positively influence consumers' satisfaction with 7 up in the study area.

3. Given the influences of the "VIEW" packaging variables on consumers" satisfaction with 7up, except for the education segments, significant variations exist in consumers' mean satisfaction with 7 up across the income and age segments considered in the study area.

\subsection{Discussion}

My previous discussions in [1,2] on the implication and significance of the influence of packaging on consumers' behavior and attitude apply here also. This study, as my other packaging studies, has implications for the academia, marketing practitioners, and consumers. In my previous discussions, I posited that in the academia, the pedagogy on marketing and formulation of marketing strategy, of which promotional strategy is part, has hitherto considered a paradigm of four Ps (product, price, promotions, and place) as pivotal. However, if methodical studies on packaging are sustained, with the increasing attention given to packaging as a key player in the promotional mix, the findings from this study also partly and further support the addition of packaging as, possibly, another ' $\mathrm{P}$ ' in the marketing mix. Packaging often represents the product itself, gives the product an image, a brand name, position/reposition, and is often the only real thing about the product that the consumer first experiences at the point of purchase, thus giving the package as serious a consideration as the product itself $[1,2]$. As I also previously discussed, actually the consumer simply buys a package of something that is, arguably, unknown until used. In this instance, when a consumer purchases 7up, the consumer simply believes that this is the famous soft drink brand with a resounding name and image as represented by the visibly scripted brand name on the package that informs or reminds the consumer of the famous 7 up. What the consumer first recognizes as 7up soft drink is the package that contains what may or may not be 7up, as claimed by the information visible on the package. The content of the bottle is simply taken to be 7 up because the visible information on the package is trusted as saying so. The content is confirmed to be 7up, for a consumer familiar with the taste of 7 up, only when the package, bottle in this case, is opened and the content is either consumed, tasted, or tested [1,2].

I also previously surmised that for the consumers, generally, methodically designed packages will not only act as the salesperson to the consumers at the point of purchase, but also as an advertising medium that conveys essential messages about the product to the consumers. Thus, a methodically designed package tends to reassure the consumers that they are getting the value for their money. Packaging, based on research findings such as uncovered in this and my other packaging studies, may be targeted at building trust and confidence in the consumers who may then retry the product further, being satisfied that the packaging informs them of attributes contained in their brand of interest. The advertising role played by a methodically designed package gives consumers adequate time to comprehend the benefits of the product as they read the information on the package, unlike some other advertising media that may not provide adequate time for consumers to comprehend the benefits of and instruction on how to use the product. Thus, the consumers become informed about the product and value for their money $[1,2]$.

For the producers and marketers, based on methodically designed packages, informed and satisfied consumers may then retry, and in time may develop loyalty to the brand. Brand loyalty, if sustained through sustained consumer satisfaction with the brand, may enhance sales, profit, and brand equity. In a competitive marketplace, methodically designed packages may be used for product positioning and repositioning, if packaging variables that influence consumer satisfaction, are identified through research, such as this study [1, 2].

As discussed above, the Information (I) and Visibility (V) components of the "VIEW" theory have significant influences on some identified consumer segments discussed above. Consequently, 7 up marketers will extract some marketing intelligence that could be used to formulate promotional strategies that will be targeted at the segments influenced by these variables.

\section{References}

[1] Akabogu, O.C. Application of the "VIEW" concept of packaging in evaluation of promotional effectiveness. Business Management Dynamics 3(1), July, 2013, 47-57

[2] Akabogu, O.C. Promotional influence of packaging on consumers' retrials of bottled water in Nigeria. Asian Academic Research Journal of Social Sciences and Humanities, 1(15), 2013, 250-268.

[3] Akabogu, O.C. Application of the "brand-choice sequences" theory to measure brand loyalty to toothpaste brands in Nigeria, Business Management Dynamics. 2(12), 2013, 33-46.

[4] Twedt, D. W. How Much Value can be added through Packaging. Journal of Marketing, 1, 1968, 55-61.

[5] Engel, J.F., Warshaw, M.R., and Kinnear, T.C. Promotional strategy, fourth edition ( Homewood, Illinois: Richard D. Erwin, Inc., 1979).

[6] Blattberg, R. C., Breiesch, R., and Fox, E.J. (1995). How Promotions work. 
[7] Rowley, J. Promotion and Marketing Communications in the Information Marketplace. Library Review, 47 (88), 1998, 383387.Marketing Science, 14(3), 1995, 122-132.

[8] Underwood, R.L. (2003). The communicative Power of Product Packaging: Creating Brand Identity via lived and mediated Experience. Journal of Marketing Theory and Practice, 11 (1), 2003.

[9] Young, S. Packaging and the Environment: A Cross-Cultural Perspective Design Management Review, 19(4), 2010, 42-48

[10] Laforet, S. (2011). Brand names on packaging and their impact on purchase preference. Journal of Consumer Behaviour, 10(2), 2011, 8-30.

[11] Fontaine, J. (2011). Promotion objectves. Retrieved from www.fontainemarketing.com

[12] Fashionmarketinglessons (2011). Package and products. Retrieved from www.fashionmarketinglessons.com

[13] Interpack (2013). Product packaging plays an important role in the marketing mix. Retrieved from http://www.interpack.com/cipp/md_interpack/ custom/ pub/content,lang,2/oid,7773/ticket,g_u_e_s_t/ / Product_packaging_plays_an_important_role_in_the_marketing_mix.html

[14] Chaneta, I. (2013). Marketing: packaging and branding. Retrieved from jupapadoc.startlogic.com

[15] CNNMoney (1994). Retreived from http://money.cnn.com/magazines/ fortune/ fortune archive/1994/08/08/79607/index.htm

[16] Nwaizugbo, I. C. Principles of marketing (Enugu, Nigeria: New Generation Ventures, 2004).

[17] Oghojafor, B. E. A., Ladipo, P.K.A., and Nwagwu, K.O. An empirical Determination of Consumers' Reaction to nutritional Labeling of pre-packaged Food Products in Lagos, Nigeria. International Journal of Development \& Sustainability, 1(2) 2, 2012, 171-185.

[18] Nigerian Population Commission (2006). Data for National Development. Retrieved from http://www.population.gov.ng/

[19] Malhotra, N.R. Marketing research, an applied orientation, Fifth Edition (Upper Saddle River, New Jersey: Pearson Prentice Hall, 2007).

[20] Meyer, E. (2013). Importance of Packaging and Branding in Marketing. Retrieved from www.ehow.com

[21] Verial, D. (2013). The Significance of Packaging. Retrieved from www.ehow.com

[22] Churchill, G.A. Jr., Marketing research methodological foundations, Second Edition ( Hinsdale, Illinois: The Dryden Press, 1979).

[23] McCarthy, E. J. Basic marketing: a managerial approach, 7ed. (Homewood, Illinois: Richard D. Erwin, Inc, 1981).

[24] Seven-Up Bottling Company Plc. (2013). Retreived from http://www.sevenup.org/home/

\section{APPENDICES (Adopted from [1, 2])}

\section{A. Data Collection Instrument}

\section{7up Package Study}

I am identified as Okey Akabogu, a doctoral marketing student at Anambra State University. I am conducting a research on how consumers who reside in this state purchase 7 up for their consumption. The information obtained from this study will be used strictly and only for the purposes of understanding the consumption of 7up in Awka, Anambra State, Nigeria, and also for the teaching of marketing in educational institutions, and marketing of 7 up for benefits of the consumers. Your name is not required for this study, and all information that you volunteer will be used only for the purposes stated above. Please, would you be kind enough to freely partake in this study by completing this short questionnaire? Your cooperation will be highly appreciated.

(QI is asked only after ascertaining that the respondents currently reside in Awka, Anambra State, and are adult consumers who have bought and consumed 7up at least once in Awka, Anambra, State, Nigeria.

QI Based on the packaging of 7up, on a scale of 1-5 as shown below, how much are you satisfied with the 7up soft drink brand? (Check one answer only.)

$5=$ Very Satisfied

$4=$ Satisfied

$3=$ Neither Dissatisfied nor Satisfied

$2=$ Dissatisfied

$1=$ Very Dissatisfied

QII Now, in thinking about the Visibility of the bottle of 7up with other canned soft drinks displayed, how much do you think that the Visibility of the bottle of 7up influences your satisfaction with 7up? (Check one answer only.)

$5=$ Very much influences

$4=$ Somehow influences

$3=$ Neutral or No opinion

$2=$ Somehow does not influence

$1=$ Very much does not influence

QIII Now, in thinking about the Information on the bottle of 7 up with other canned soft drinks displayed, how much do you think that the Information on the bottle of 7up influences your satisfaction with 7up? (Check one answer only.)

$5=$ Very much influences

$4=$ Somehow influences

$3=$ Neutral or No opinion

$2=$ Somehow does not influence

$1=$ Very much does not influence 
QIV Now, in thinking about the Emotion (color and shape) of the bottle of 7up with other canned soft drinks displayed, how much do you think that the Emotion (color and shape) of the bottle of 7 up influences your satisfaction with 7up? (Check one answer only.)

$5=$ Very much influences

$4=$ Somehow influences

$3=$ Neutral or No opinion

$2=$ Somehow does not influence

$1=$ Very much does not influence

QV Now, in thinking about the opening, closing, and preservation of the contents (Workability) of the bottle of 7 up on display with other canned soft drinks displayed, how much do you think that the opening and closing, and preservation of the contents (Workability) of the bottle of 7 up influences your satisfaction with 7 up. (Check one answer only.)

$5=$ Very much influences

$4=$ Somehow influences

$3=$ Neutral or No opinion

$2=$ Somehow does not influence

$1=$ Very much does not influence 